\title{
Novel robot arm design and implementation for hot forging press automation
}

\author{
Chu A My ${ }^{\mathrm{a}^{*}}$, Chi Hieu Le ${ }^{\mathrm{b}}$, Michael Packianather ${ }^{\mathrm{c}}$, Erik L J Bohez ${ }^{\mathrm{d}}$ \\ ${ }^{a}$ Department of Special Robotics and Mechatronics, Le Quy Don Technical University, 236 \\ Hoang Quoc Viet, Hanoi, Vietnam; \\ ${ }^{b}$ Faculty of Engineering and Science, University of Greenwich, Central Avenue, Chatham \\ Maritime, Kent ME4 4TB, United Kingdom; \\ ${ }^{c}$ School of Engineering, Cardiff University, Queen's Buildings, The Parade, Cardiff CF24 3AA, \\ United Kingdom. \\ ${ }^{d}$ School of Advanced Technologies, Asian Institute of Technology, Klongluang, Pathumthani \\ 12120, Bangkok, Thailand; \\ *Corresponding author. Email: mychuanh@yahoo.com
}




\title{
Novel robot arm design and implementation for hot forging press automation
}

\begin{abstract}
Manual handling of hot and heavy workpiece in forging press industry increases the process time and causes safety risks to workers. To increase the productivity and optimize the use of manpower, manipulators are needed to be designed for supporting the workers handling the workpiece. Designing robots for such applications is challenging since the robot suffers from a heavy payload at the arm tip, and it operates at a high speed in a large workspace. This research addresses the design and implementation of a novel robot for handling workpiece for a given forging press cell. A novel robotic mechanism is designed with two key features: (i) the addition of parallel links in between serial links, and (ii) the use of hydraulic actuators for driving robot's joints. The addition of parallel links and the use of hydraulic cylinders are to increase the structural rigidity. It is also to reduce the number of joint variables and restrict the end-effector moving parallel to the ground surface so that the robot grips and releases the workpiece in a more efficient and simplified manner. The effectiveness of the designed robot mechanism is demonstrated through functional tests, and experimental results are carried out on the implemented robot.
\end{abstract}

Keywords: Design of production systems; robotic cells; productivity improvement; robot systems; robot applications; robot grippers; material handling; forging press; serial-parallel robot

\section{Introduction}

Hydraulic hot forging press is the process of shaping a hot workpiece that is placed in a die by applying hydraulic pressure. This type of forging is usually done on a forging press machine which applies gradual pressure on the forging die. A manufacturing cell of hot forging press usually consists of two main components: a heating furnace and a forging press machine. The hot forging press process includes two main steps: the workpiece heating and the workpiece forging. In practice, one of the most important aspects of the manufacturing process is related to the material transfer which significantly impacts on the productivity and the safety issue for workers. 
As stated by Gougar et al. (2002), efficient and timely material transfer is becoming critical in manufacturing systems. The speed with which a workpiece in process is transferred has a direct and obvious impact on the quality of the product and the throughput of the manufacturing system. Furthermore, factory management, organization and scheduling decisions are significantly influenced by the efficiency of the material transfer system, which in turn affects the productivity and competitiveness of the manufacturing system as a whole (Gultekin et al. 2008, Yildiz et al. 2011, Sriskandarajah \& Shetty 2017, Boudella et al. 2018). Though the efficiency of manufacturing systems is much affected by the material transfer, manual methods of material handling have been widely used in forging industry. The use of manual methods increases the downtimes and causes safety and health risks and environmental hazards to workers since the workers grasp and move directly the working piece with tongs. As for costs of using robots in industries, Tilley (2017) reported that as robot production has increased, costs have gone down. Over the past 30 years, the average robot price has fallen by half in real terms, and even further relative to labour costs. These critical issues have motivated and encouraged the implementation of innovative robot design for the material handling. However, designing a robot arm for the mentioned application usually copes with challenges since the robot usually suffers from a heavy payload at the arm tip, and it must operate at high speed in a large operational space. As for the given forging press workshop under consideration in this research, the designed robot is required to handle workpiece weighted about $60 \mathrm{~kg}$. It must transfer a heated workpiece along a distance of $2.5 \mathrm{~m}$, the distance between the heating furnace and the press machine, within a limited time period of $20 \mathrm{sec}$. This is a critical task for the design of robot.

Notice that, in the robot market, there have been some kinds of high payload industrial robots such as products of Kuka High Payload Robot Series or Fanuc M-2000 Series that can be selected for 
the application. However, if such a robot is selected for the application, the griper of the robot could be redesigned, other components related to the griper could be revised, fixtures could be added, and much work on experimental integration and testing must be carried out. Hence, the integration of the robot for the application could be not economical and inefficient.

This paper presents the design and implementation of a novel robot arm capable of replacing workers to grasp and transfer workpiece among the components of a given forging press manufacturing system. For the arm design, a novel robotic mechanism is designed with two special features: (i) two successive parallel links are added in between serial links, and (ii) hydraulic cylinders are selected for driving active joints of the robot. The addition of parallel links and the use of hydraulic cylinders as auxiliary links appended to the robot architecture are necessary to increase the structural rigidity of the arm. Besides, the combination of the parallelserial links reduces the DOFs of the mechanism and restricts the end-effector moving parallel with the ground surface as desired. The reduction of the DOFs leads to reduce the number of actuators deriving the robot so that it simplifies the control system. Since the orientation of the end-effector is optimized, the robot grips and releases the workpiece in an efficient and simple manner. It also improves the positioning accuracy and repeatability of the gripper. Additionally, the workpiece is always oriented in either vertical direction or horizontal plane only so that it increases the stability and stiffness of the arm while moving a heated workpiece at high speed.

The design of the arm is then validated via kinematic performance analysis, quasi-static modelling and analysis, and structural performance simulation. Notice that the kinematic modelling of the designed robot is more complicated than that of conventional serial arm, because of the hybrid serial-parallel feature of the robot architecture. The kinematical constraint equation must be formulated and put together with the kinematic model. Based on the entire kinematic model 
formulated, the inverse kinematics and the transferring time are analysed and discussed to demonstrate the kinematical performance. In addition, to investigate the structural characteristics of the end-effector module, the static displacement and the stress distributed on module's components are computed and simulated by using the computer-aided finite element method (FEM). Besides, to analyse the applied torques imposing on the robot system, the quasi-static model is formulated as well. Thus, the loading capability of the selected hydraulic cylinders can be assessed and discussed. Finally, the effectiveness of the designed system is demonstrated through functional tests and experiments. The testing results demonstrate the working performance of the designed system. By applying the robotized solution, the average cycle time of the production is reduced by $27.7 \%$ approximately.

It is noticeable that the hot forging press process under consideration is different from the open-die forging process mentioned in researches by Yan et al. (2010), Chen et al. (2012), Faguo et al. (2008) and Ding et al. (2017). The manipulators designed for the open-die forging is to hold and manipulate a workpiece for the forging process, whereas the robot arm presented in this work is designed to pickup, transfer and release workpiece among given positions in a large workspace of a hot forging press cell.

\section{Related work}

The use of robots for industrial applications is a practice, which has started years ago. Early designs of robotic systems concentrating on industrial manipulators are mostly to perform tasks such as welding, painting, and palletizing (Garcia et al. 2007). The state of the art in robotics can be found out in the report by Forge and Blackman (2010). In the literature, there are two main categories of researches focusing on the design and integration of robotic systems for 
manufacturing cells. The first category concentrates on the use of general purpose robots (commercial robots), and the second one aims at designing and implementation of robotic systems. In the first approach, commercial robots are selected and used to perform required tasks. Related to this issue, Olsson et al. (2010) uses a light-weight industrial robot for high-precision drilling system, based on the technique of high-performance force/torque control. Denkena \& Lepper (2015) investigates a cost-effective manufacturing of large frame parts for aerospace industry with an industrial robot of low stiffness of the robot structure. Huang \& Lin (2002) develops a robotic cell, in which two industrial robots are used for manufacturing complex objects. The system is shown to be flexible, reconfigurable, automatic, and capable of manufacturing complex prototypes in the current industry environment.

The optimal selection of robots for robotic cells is investigated by several authors as well. Karsak (2008) introduces a decision model based on quality function deployment and fuzzy linear regression. Kentli \& Kar (2011) proposes a multi-criteria model using satisfaction function to convert various robot attributes into a unified scale. A distance measure technique is also used to ascertain the highest ranked candidate-robot. Liu et al. (2014) handles the robot selection issue with respect to uncertainties and incomplete information. This method considers both subjective judgements and objective information in real-life applications, and models the uncertainty and diversity of decision-makers' assessments using interval 2-tuple linguistic variables.

As for the robot - human collaboration, Michalos et al. (2014) proposes a hybrid solution that involves the safe cooperation of operators with an adapting robotic system for an industrial assembly process. The focus is given to combining robot strength, velocity, predictability, repeatability and precision with human intelligence and skills. Michalos et al. (2010) shows that the costs associated with delivering raw materials, moving work in process and removing finished 
goods, need to be minimized. At present, the automotive industry and its supply chains are main users of robotic systems, due to their ability to accomplish tasks (assembly, inspection etc.) of improved quality and repeatability. In the research by Cherubini et al. (2016), a collaborative human-robot mechanism for an assembly cell is considered where the robot alternates active and passive behaviors during assembly. Thus, the human workload is reduced, diminishing the risk of strain injuries.

The optimal use of industrial robots is significantly influenced by algorithms for tool path generation, and solutions for the task planning and sequencing. Dolgui and Pashkevich (2009) addresses a technique to optimize the tool path generation for laser cutting robotic systems. The proposed optimisation emphasises on a six-axis robot motion for continuous contour tracking while considering the redundancy caused by the tool axial symmetry. In the research by Dolgui \& Pashkevich (2006), an effective method for welding operations planning is presented for a robotic cell with a positioning table. Besides, to increase the productivity of robotic cells, there is a number of reported researches, which mostly deal with the sequencing and scheduling issue. Galante \& Passannanti (2006) presents the dimensioning and the scheduling of a material handling system, constituted by more than one dual-gripper robot tending a manufacturing serial system. Gultekin et al. (2008) solves the robotic cell scheduling problem with M-machines under the assumption of process and operational flexibility. Yildiz et al. (2011) deals with the scheduling issue arising in an $\mathrm{M}$-machine robotic cell consisting of $\mathrm{CNC}$ machines to minimise the cycle time and the manufacturing cost simultaneously. Foumani et al. (2014) studies the scheduling of a rotationally arranged robotic cell with the multi-function robot. This is to minimise the steady-state cycle time for identical part production. Kovács (2016) investigates the integrated task sequencing and path planning in robotic cell of laser welding to finding the appropriate order of welding tasks. 
Yang et al. (2016) provides with a solution to the scheduling problem for a robotic manufacturing cell with multiple robots. Kim et al. (2017) presents a scheduling strategy which controls robot task timings. It is to optimize the scheduling for sequentially connected cluster tools with dualarmed robots with a single input and output module, which includes multi-cluster tools and linear cluster tools. He et al. (2016) investigates the part input sequencing and scheduling in flexible manufacturing systems in a mass customisation/mass personalisation environment. Both robot and machine scheduling rules using a state-dependent part input sequencing algorithm are taken into account. Thomasson et al. (2018) introduces the twin robot palletising problem in which two robots must be scheduled and routed to pick up and deliver products at specified locations along a rail. Sriskandarajah \& Shetty (2018) examines the recent theoretical developments on the analysis of throughput optimisation in robotic cells served by a dual-gripper robot. The research focuses on the scheduling operations in dual-gripper robotic cells that produce identical parts. The objective of the work is to find a cyclic sequence of robot moves that minimises the long-run average time to produce a part or, equivalently, maximises the throughput. Boudella et al. (2018) optimizes the assignment of stock keeping units for a hybrid kitting system that consists of a robot and an operator working in series to deliver parts to an assembly line so that the cycle time of the overall system is optimized.

In the second approach, noticeable attempts have been made to design and implement new robots for a wide spectrum of applications. Gougar et al. (2002) presents a method to design a high-speed robot with cycle times comparable with the existed material transfer system using linear induction motors. A generic design methodology is developed for robot manipulators that integrates several key design issues such as kinematics, dynamics, structural mechanics, actuator sizing, assessing robustness to parameters and sensor errors, and vibration analysis. Tor et al. (2008) introduces an 
expert functional design model based on the designers' behavior-driven, function-environmentstructure formalism, which is tailored to meet the special requirements of industrial robot design. Years ago, particular robots have been increasingly designed and implemented: the high speed manipulator for lazer cutting applications (Youcef-Toumi \& Kuo 1989), the high performance loading robot for a tool-delivery system (Gougar et al. 2002), the hybrid mobile robots (Paolo and Botturi 2008), the leg-wheel robot (Wei et al. 2017), the easy-to-use modular assistive robotic system (Kim et al. 2014), etc.

Parallel robots and serial-parallel robots have been investigated in the literature also. $\mathrm{Pa}$ and $\mathrm{Wu}$ (2012) and Jin et al. (2009) introduce the designs of parallel robot for the open die forging. There has been a number of researches focusing on the forging manipulator - a kind of hybrid serialparallel robots, of which issues related to the modelling and analysis are discussed by Yan et al. (2010) and Chen et al. (2012), and the synthesis of mechanism is considered by Faguo et al. (2008) and Ding et al. (2017). Considering the hybrid serial-parallel structure, Pinskier et al. (2018) addresses a master-slave manipulator consisting of a 4-DOF hybrid parallel-serial slave mechanism. Carbone \& Ceccarelli (2005) presents a serial-parallel manipulator by investigating the feasibility of combining two different robotic structures into one robot.

Notice that, though a diversity of general purpose robots has been used for manufacturing systems, and much research related to the optimization of robotic cell performance has been carried out, which demonstrates advantages of the use of general purpose robots, commercial industrial robots are commonplace, they best perform a set of given tasks, and they do not guarantee optimal task execution. Dolgui and Pashkevich (2009) remarks that there still exists a considerable gap between the capabilities of commercial robotic systems and the requirements rising from specific applications. This exiting gap has motivated the developments of a wide spectrum of particular 
robotic systems which guarantee the task completion effectively. Moreover, recent advances in robotic technology also motivates the design and implementation of particular robots to meet the increasing demand in industrial manufacturing. New concepts of robotic system are increasingly investigated, based on the prior knowledge of application of manipulators as well as the decomposition of required tasks. More and more innovative robotic architectures have been coming out. In this context, one of such the innovative robotic systems is presented in this research: the hybrid serial - parallel robot arm transferring heavy workpiece for a hot forging press manufacturing system.

Notice further that, most of the reviewed robotic systems are mainly robot arms having serial architecture. However, robots having this type of architecture suffer with several known drawbacks. The serial architecture suffers from a low loading capability, a relatively low stiffness, low normal payload/weight ratio, limited reachable workspace, etc. These aspects are critical for tasks such as the heavy workpiece transfer for manufacturing cells of forging press. In contrast, parallel robots present very good performances in terms of rigidity, accuracy, etc. Moreover, Carbone \& Ceccarelli (2005) shows that the combination of two different robotic structures into one system can be used as a hybrid system in which stiffness, singularity and accuracy can be optimized as related to workspace demands and motion restrictions that are required for a priori selected applications. The advantages of the hybrid serial-parallel robotic structure also motivates the synthesis of the mechanism for the robot arm addressed in this paper.

\section{Functional requirements and task description for the robot design}

The main functional requirements for the designed robot are that the robot must be capable of replacing workers to grasp, transfer and release hot and heavy workpiece among given places of the given forging workshop. It is required to operate at high speed in a large operational space so 
that the cycle time for the production is reduced. The maximum payload imposing on the arm tip of the robot is $60 \mathrm{~kg}$, the reachable workspace approximates a cube with dimensions $2500 \mathrm{~mm} \mathrm{x}$ $2500 \mathrm{~mm} \times 2500 \mathrm{~mm}$, the maximum transferring time for transferring a heated workpiece from the furnace to the machine is $25 \mathrm{sec}$, and the maximum positioning error of the end-effector is $5 \mathrm{~mm}$. The designed robot is required to perform the main tasks as below.

Task 1. Loading a raw workpiece and moving it from the loading area to the heating furnace. At the beginning of a forging press cycle, the robot arm (depicted in Fig. 1) must grasp a raw workpiece prepared at a given place. Then the robot moves and places the workpiece onto the table of the heating furnace.

Task 2. Grasping the heated workpiece and moving it from the furnace to the forging press machine. After the heating process completed, the hot workpiece must be transferred to the forging press machine, and this is an important task of the arm. The arm is required to pickup the workpiece and move it as fast as possible from the furnace to the machine.

In order to identify the required movements of the end-effector, the two main tasks need to be decomposed in detail. In Fig. 2a, the tasks are characterized by two routines of the workpiece movement. The routine A includes steps A1, A2 and A3, characterizing the manipulative trajectory of a raw workpiece. The grasping of a raw workpiece at the beginning and the movement of the grasped piece to a given position in front of the heating furnace are denoted by Step A1 of the routine A. Step A2 is the movement of the end-effector grasping the piece from the previous position into the furnace. Step A3 denotes the movement of the end-effector placing and releasing the workpiece on the table of the furnace. 

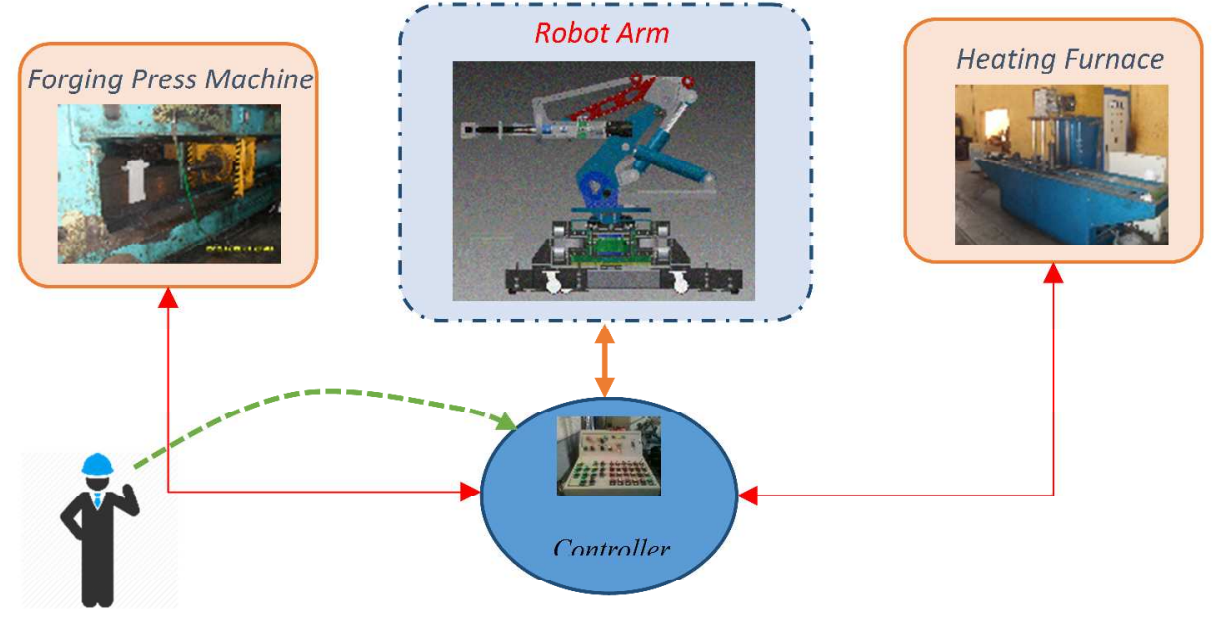

Fig. 1. Schematic diagram of the designed robot

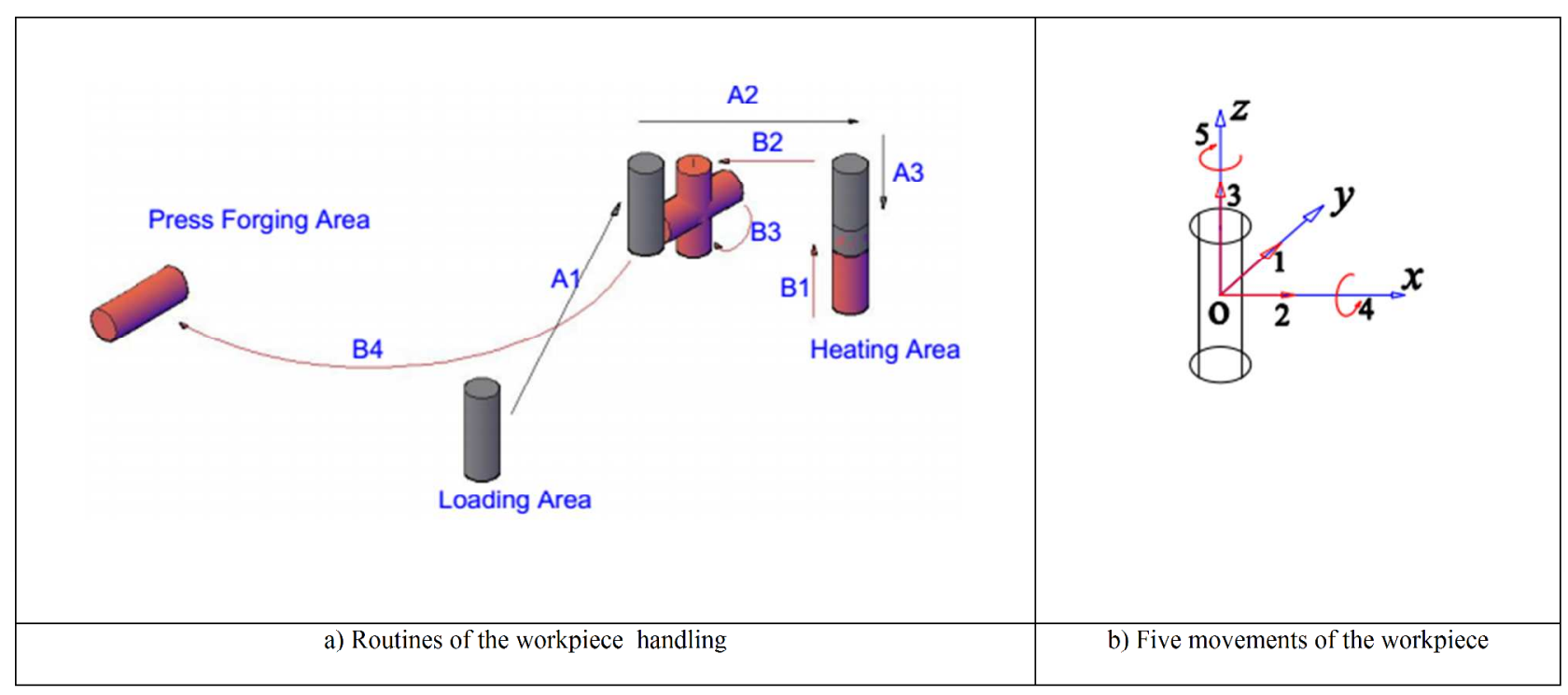

Fig. 2. Manipulative task description for robot arm

The second one (routine B) represents the trajectory of the heated workpiece moving from the furnace to the forging machine (B1, B2, B3 and B4). Step B1 is the picking up of a heated workpiece, step B2 is the backward movement out of the furnace, step B3 is a $90^{\circ}$ turn of the workpiece, and step B4 is the transferring of the workpiece to the fixture on the forging machine. Based on the tasks decomposed, five movements of the workpiece required to perform by the arm are determined as shown in Fig $2 \mathrm{~b}$. In the coordinate system Oxyz defined in the workspace, the movements 1,2 and 3 are the linear displacements, and the movements 4 and 5 are angular 
displacements, respectively. Notice that, with the purpose of increasing the ease for the endeffector while grasping and moving a workpiece, the manipulating piece is desired to be oriented in either vertical direction or horizontal plane. This orientation of the workpiece is also expected to increase the stability of the arm manipulation, and reduce the positioning error of the end-effector. For this reason, the end-effector needs to be controlled so that the desired orientation of the workpiece can be yielded. To simplify the control of the robot, it is necessary to design the arm mechanism such that the end-effector is always orientated in parallel with the ground surface, without any control procedure. This is a very important constraint for the arm design.

\section{Structure design for the robot arm}

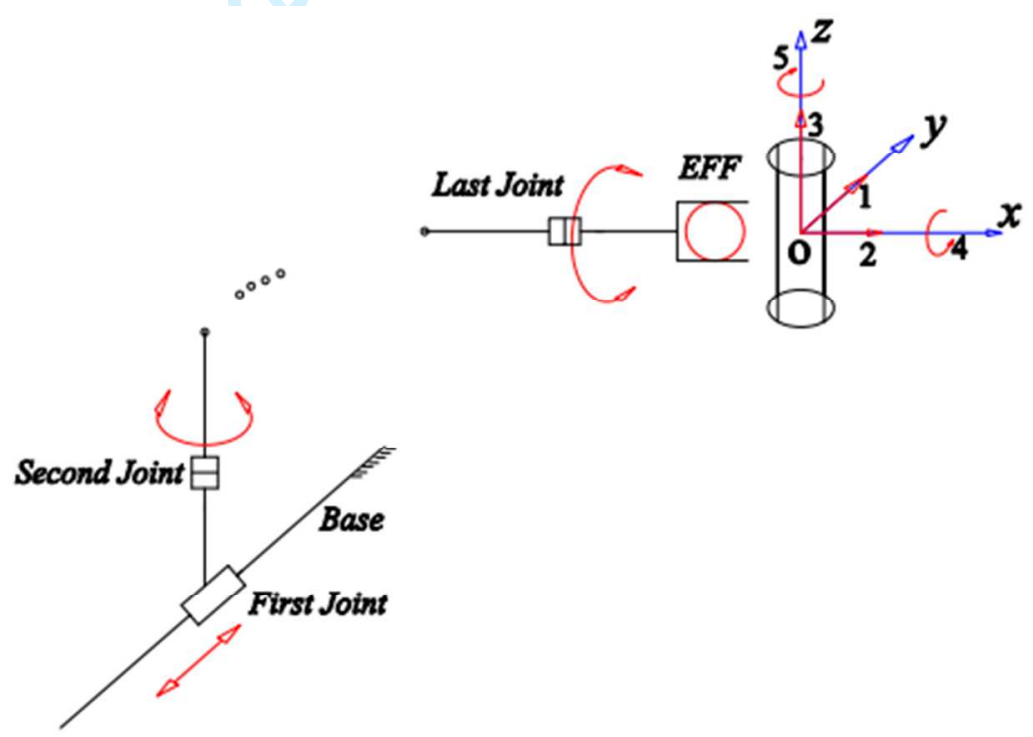

Fig. 3. The selection of the first, the second and the last joint

Suppose that the kinematic chain synthesized for the designed arm comprises of rigid links jointed by kinematical joints with one degree of mobility (revolute joints $(\mathrm{R})$ and prismatic joints $(\mathrm{P})$ ). Generally, to perform the five movements of the workpiece as required, the arm needs to be designed with a serial link mechanism of at least 5 DOFs. Theoretically, there are $2^{5}$ feasible configurations of the five DOFs mechanism that could be considered to find out the optimal one. 
Fortunately, to grasp and release objects like the cylindrical workpiece under consideration, a 1DOF two-pin gripper is widely used in the automation of manufacturing processes because of its low cost and high reliability (Pham et al. 1991, Su et al. 2017). Also, an R joint is often selected to connect this gripper with the previous link (Fig. 3). In this approach, the two pin gripper is selected for the end link design. Thus the rotation 4 (the task B3) can be successfully performed with the designed end-effector and the selected joint. To fulfil the task A1 (the movement 1), the arm needs to be travelled along $O y$ axis in the workspace. A prismatic joint is a suitable selection for the first joint design which connects the arm with a base fixed on the ground surface. See Fig. 3. The selection of the second joint relates to the execution of the task B4 transferring a heated piece from the furnace to the machine. To do this important task, a translational movement of the arm at high speed is not suitable because of a long distance existed between the furnace and the press machine. A rotation of the arm about the second joint is more feasible since a small rotational angle of the joint could induce a large displacement of the arm tip. Thereby, an $\mathrm{R}$ joint is selected for the second joint of the arm (Fig. 3).

The selection of the first, the second and the last joints reduce the DOFs of the synthesizing mechanism by three. The remained part of the mechanism, which connects the second joint with the last joint, needs to be synthesized to take the two translations 2 and 3 of the workpiece into account. To perform the two translations simultaneously in vertical plane and restrict the endeffector moving parallel with the horizontal surface, planar kinematic chains of two DOFs and three DOFs can be considered. In theory, there are $2^{2}$ feasible configurations of two DOFs (RR, PP, PR, and RP) and $2^{3}$ configurations of three DOFs (RRR, RRP, RPR, RPP, PPP, PPR, PRP, and PRR) that could be considered for the synthesis of the remained part of the arm mechanism. 
Among the configurations of two DOFs, only the configuration PP shown in Fig. 4a is feasible since it satisfies the motion constraint. Among the configurations of three DOFs, only RRR, RPR, PRR and RRP presented in Figs. 4b-4e are considerable because the configurations PPP and PPR equivalent to the configuration PP, and the configurations RPP and PRP are impossible to orient the end link in the horizontal direction.

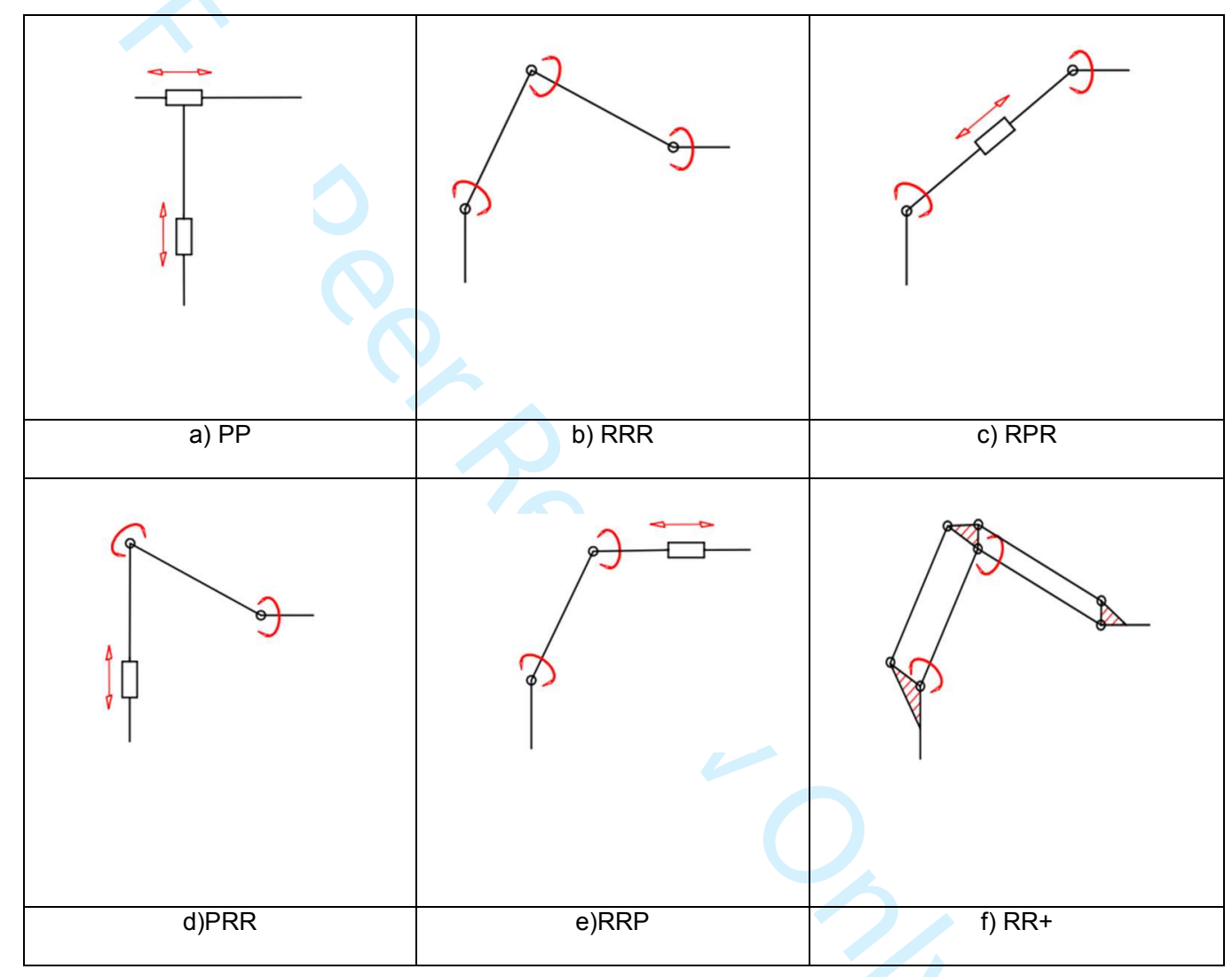

Fig. 4. Feasible configurations of the remained part of the synthesizing mechanism

It is worth to notice that if two parallel links are added to the configuration RRR, a particular configuration RR+ is obtained as shown in Fig. 4f. Particularly, this configuration has only two DOFs. By using this configuration, not only the two movements 2 and 3 of the workpiece can be performed but also the required orientation of the end-effector is yielded. 
Table 1. Main advantages of the configurations

\begin{tabular}{|c|c|c|c|}
\hline Configurations & Advantages & Disadvantages & $\begin{array}{c}\text { Remark } \\
\text { (*: strong } \\
\text { point) }\end{array}$ \\
\hline$P P$ & - Less active joints & $\begin{array}{l}\text { - Less flexible movements } \\
\text { - Less rigid structure }\end{array}$ & $*$ \\
\hline $\begin{array}{l}R R R, R P R \\
P R R, R R P\end{array}$ & - More flexible movements & $\begin{array}{l}\text { - More active joints } \\
\text { - More complex control to orient the EFF } \\
\text { - Less rigid structure }\end{array}$ & $*$ \\
\hline$R R+$ & $\begin{array}{l}\text { - Less active joints } \\
\text { - More rigid structure } \\
\text { - More flexible movements }\end{array}$ & $\begin{array}{l}\text { - Passive joints added } \\
\text { - Auxiliary links added }\end{array}$ & $* *$ \\
\hline
\end{tabular}

As shown in Tab. 1, the most important advantage of the configurations PP and RR + is that they have only two DOFs in comparison with the three DOFs configurations. This reduces the number of actuators and the complexity of the control system. As compared to the configuration $\mathrm{RR}+$, the configuration PP has some disadvantages. To perform a movement of a workpiece in the vertical plane, the combination of two translational movements produced by the configuration PP is less flexible than the combination of two rotational movements by the configuration RR+.

Furthermore, the length parameter of the second link of the PP structure is designed which depends on the distance existed between the furnace and the press machine requires, and a counterweight could be added to the link. Fortunately, the use of configuration RR+ overcomes all of the mentioned weak points. The two rotational joints make it more flexible to move the workpiece in vertical plane. The addition of two parallel links increase the structural stiffness and makes it better payload-to-weight ratio. In addition, two hydraulic cylinders are able to use as auxiliary links to reinforce the structural rigidity of the entire robot (Fig. 5c). Moreover, there is no counterweight is needed to balance the shaking force. 


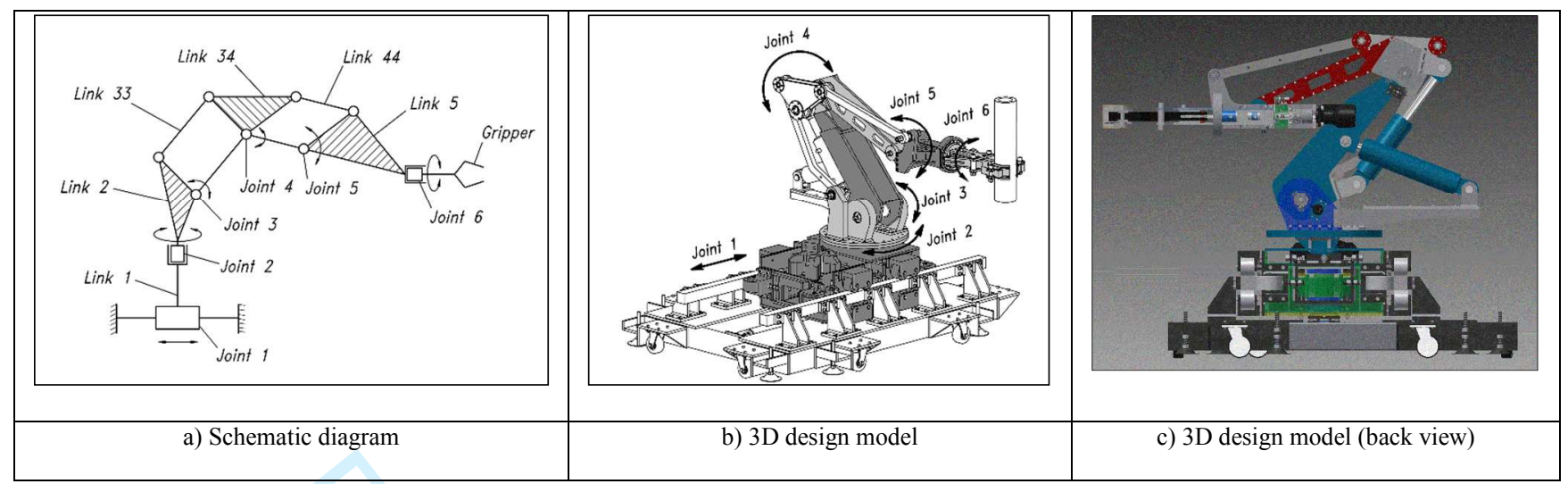

Fig. 5. The mechanism of the robot arm and its design

Finally, the configuration RR + is selected to complete the kinematic chain of the arm mechanism, of which the schematic diagram is presented in Fig. 5a, and the 3D design model are shown in Figs. $5 \mathrm{~b}$ and $5 \mathrm{c}$. Notice that the joint number 5 is passive; there is no actuator needed for driving this joint.

The 3D simulation model of the designed robot is depicted in the following figure.

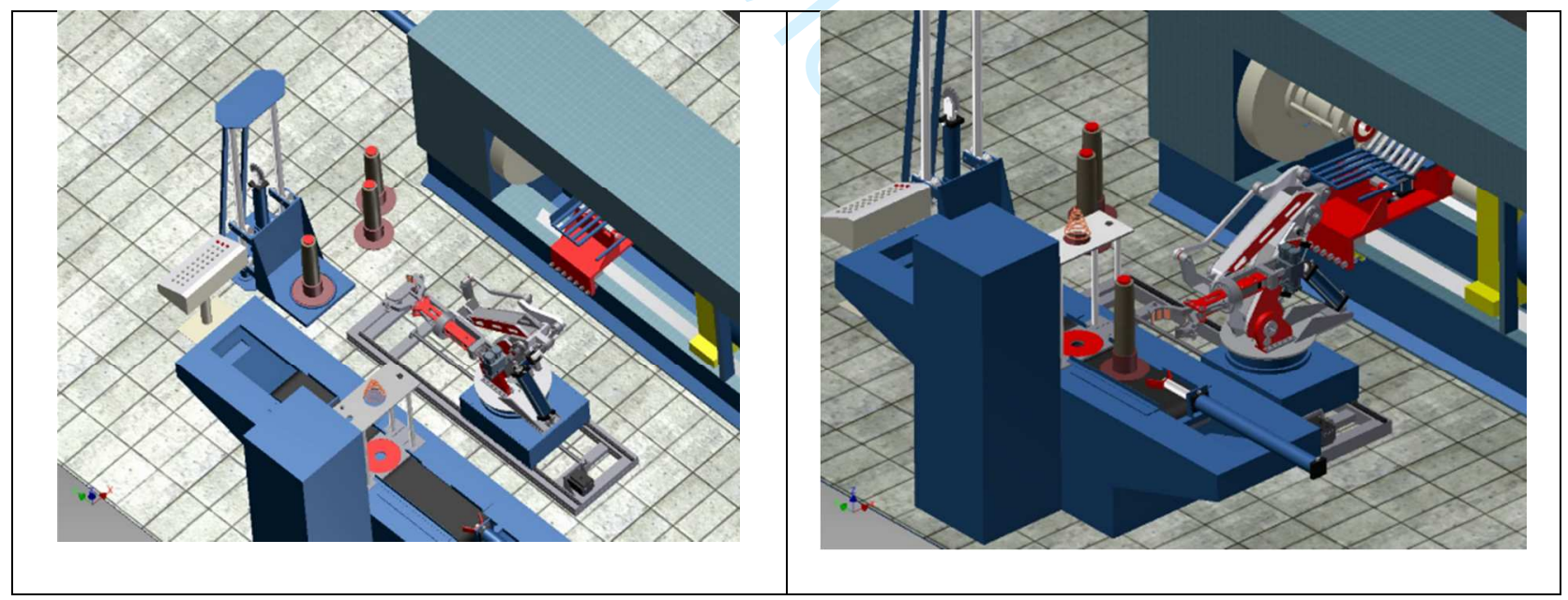

Fig. 6. 3D model of the designed robot in workspace 


\section{Validation and testing}

In this section, validation procedures for the designed robot are investigated. The kinematic modelling and analysis is summarized to validate kinematic performance of the arm, and to select proper parameters for links 3 and 4. The quasi-static model is formulated to analyse the applied torques imposing on the system. Thus, the loading capability of the selected hydraulic cylinders can be assessed. In addition, the deflection of the arm end link is checked through a simulation model. Finally, functional tests and cycle time analysis are carried out to demonstrate the effectiveness of the implemented robot. Notice that the quasi static analysis, the real robot implementation, the testing procedures and experiments carrying out on the implemented robot are the main and important contents. The kinematic analysis and the elastic displacement simulation of the last link that are relevant to previous papers (My 2016, My \& Parnichkun 2015) are summarized with the purpose of completing the overall validation procedure as a whole.

\subsection{Kinematic modelling and analysis}

\section{Kinematic modelling}

On the kinematic model (Fig. 7), $O_{0} \equiv\left(O_{0} x_{0} y_{0} z_{0}\right)$ is defined as the reference frame; $O_{1}, O_{2}, \ldots$, and $O_{6}$ are the link frames, correspondingly; $\mathbf{q}=\left[\begin{array}{llllll}d_{1} & q_{2} & q_{3} & q_{4} & q_{5} & q_{6}\end{array}\right]^{T}$ is the vector of joint variables; $a_{i}$ and $\alpha_{i}$ are the kinematical and geometrical parameters of the link indexed $i$. The coordinate systems 1' and 5' are added to write all the homogeneous transformation matrices of the whole system in the same formulation by Denavit-Hartenberg, $\mathbf{H}_{j i}\left(q_{i}, d_{i}, a_{i}, \alpha_{i}\right)$. The matrix $\mathbf{H}_{j i}$ characterizes the homogeneous motion of the frame indexed $i$ 
with respect to the preceded frame indexed $j$. Notice that the joint 5 is passive, so $q_{5}$ is a dependent joint variable which relates to $q_{3}$ and $q_{4}$ in the following constraint equation.

$$
q_{5}=-q_{3}-q_{4}-\frac{p}{2}
$$

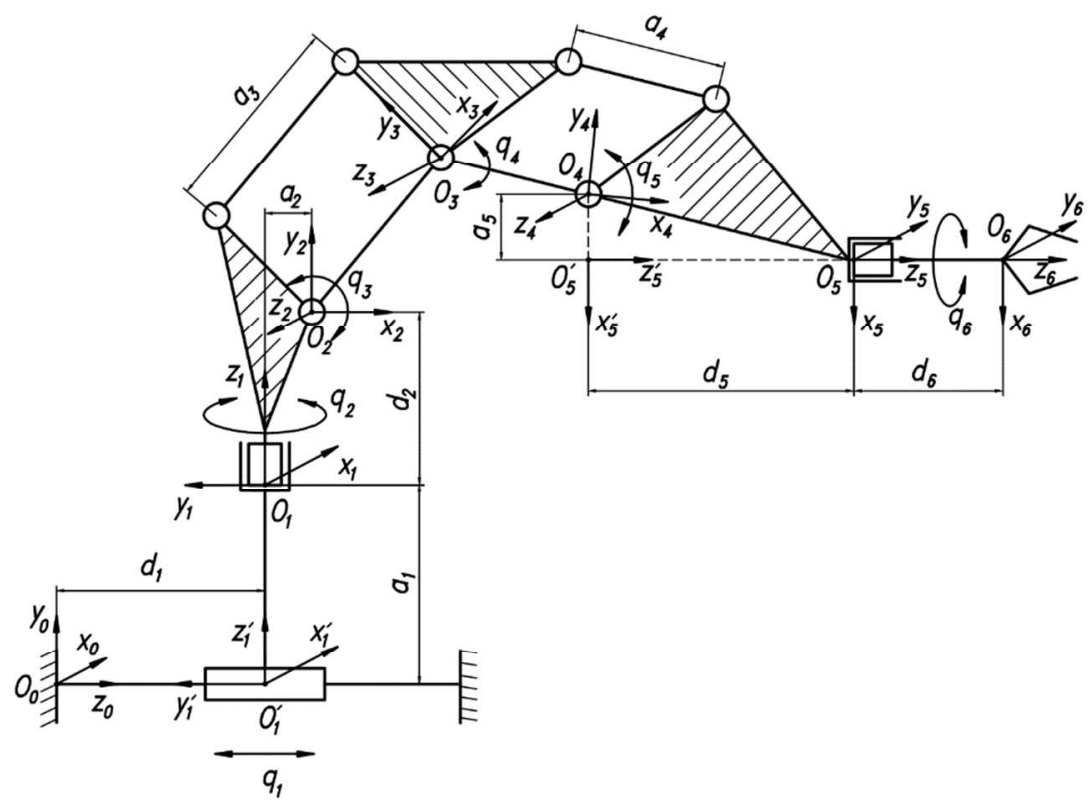

Fig. 7. Kinematical model

In the reference frame, the homogeneous transformation matrix of the end-effector can be calculated as

$$
\mathbf{H}_{0 E}=\mathbf{H}_{01^{\prime}}\left(d_{1}\right) \mathbf{H}_{1^{\prime} 1} \mathbf{H}_{12}\left(q_{2}\right) \mathbf{H}_{23}\left(q_{3}\right) \mathbf{H}_{34}\left(q_{4}\right) \mathbf{H}_{45^{\prime}}\left(q_{5}\right) \mathbf{H}_{5^{\prime} 5} \mathbf{H}_{56}\left(q_{6}\right)
$$

In matrix form, (2) can be rewritten as

$$
\mathbf{H}_{0 E}=\left[\begin{array}{cc}
\mathbf{A}(\mathbf{q}) & \mathbf{r}(\mathbf{q}) \\
0 & 1
\end{array}\right],
$$

where $\mathbf{A}(\mathbf{q})$ is the rotation matrix, and $\mathbf{r}(\mathbf{q})$ is the translation vector of the end-effector. Equation (3) describes the forward kinematic relationship of the robot. If we denote 
$\mathbf{p}_{E}=\left[\begin{array}{lllll}x_{E} & y_{E} & z_{E} & \gamma & \beta\end{array}\right]^{T}$ representing the general position of the end-effector in $O_{0}$, where $\gamma$ is the yaw angle and $\beta$ is roll angle of the end-effector, (3) can be rewritten as the following equation.

$$
\mathbf{p}_{E}=\mathbf{f}(\mathbf{q})
$$

Equation (4) has 5 independent variables. Substituting (1) into (4), and solving for $\mathbf{p}_{E}$ yields

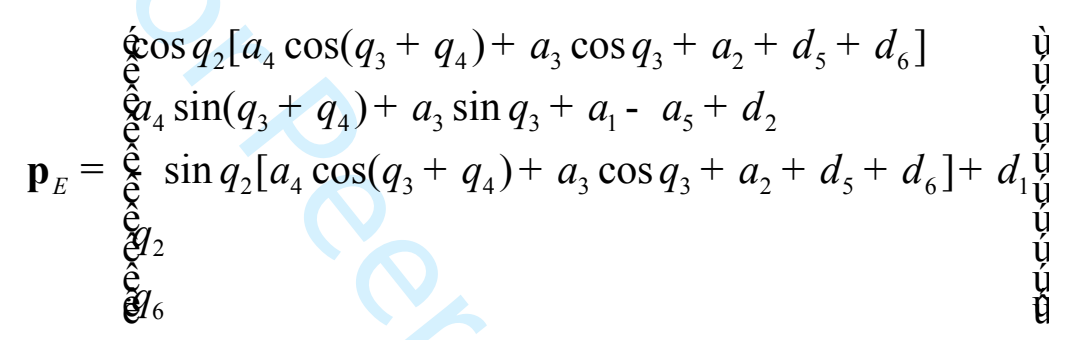

Equation (5) is the forward kinematic equation for the arm.

\section{Inverse kinematics}

Based on (4), the value of joint variables is found out by solving the inverse function $\mathbf{q}=\mathbf{f}^{-1}\left(\mathbf{p}_{E}\right)$. Thus the analytical solution of the inverse kinematics is yielded as follows.

$$
\left[\begin{array}{l}
d_{1} \\
q_{2} \\
q_{3} \\
q_{4} \\
q_{6}
\end{array}\right]=\left[\begin{array}{c}
x_{E} \tan q_{2}+z_{E} \\
\gamma \\
\tan ^{-1}\left(\frac{-b+\sqrt{b^{2}-4 a c}}{2 a}\right) \\
\cos ^{-1}\left(\frac{\left(\frac{x_{E}}{\cos q_{2}}-A\right)^{2}+\left(y_{E}-B\right)^{2}-a_{3}^{2}-a_{4}^{2}}{2 a_{3} a_{4}}\right) \\
\beta
\end{array}\right]
$$


where $A=a_{2}+d_{5}+d_{6} ; B=a_{1}-a_{5}+d_{2} ; a=-\left(y_{E}-B\right)^{2}+\left(a_{4} \cos q_{4}+a_{3}\right)^{2}$;

$b=2 a_{4} \sin q_{4}\left(a_{4} \cos q_{4}+a_{3}\right) ; c=-\left(y_{E}-B\right)^{2}+a_{4}^{2} \sin ^{2} q_{4}$.

Equation (6) shows that for any point $\mathbf{p}_{E}=\left[\begin{array}{lllll}x_{E} & y_{E} & z_{E} & \gamma & \beta\end{array}\right]^{T}$ given in the workspace, the value of joint variables can be determined analytically. By implementing (6), for the case of the heated workpiece transfer, the time history of joint displacements

$d_{1}(t), q_{2}(t), q_{3}(t), q_{4}(t)$, and $q_{6}(t)$ are calculated and shown in Fig. 8. In this implementation, the geometric parameters of the links are given as $a_{1}=0.11 \mathrm{~m}, d_{2}=0.25 \mathrm{~m}, a_{2}=0.1 \mathrm{~m}$, $a_{3}=0.73 m, a_{4}=0.63 m, a_{5}=0.18 m, d_{5}=0.03 m$ and $d_{6}=0.43 m$. Notice that, Spline function in Matlab programming language is utilized to interpolate the trajectory of the end-effector in time domain.

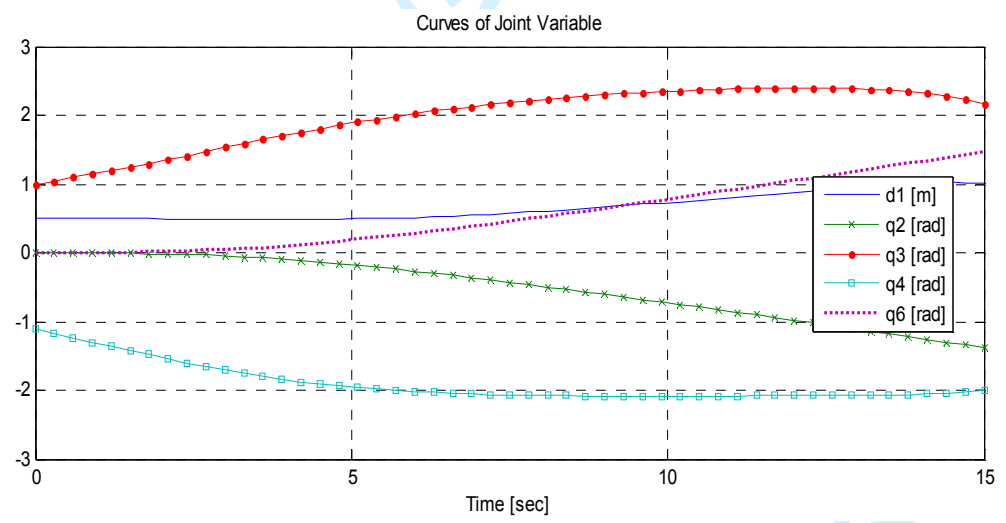

Fig. 8. Time history of joint variables

By using this inverse kinematic analysis, for any given task assigned to the designing robot, the operation of the robot can be demonstrated and the feasibility of the joint variables varying can be checked as well. It is essential for the robot program to control the end-effector moving at a required velocity along the desired trajectory in the workspace. It is important that the path 
planning and the kinematic analysis also simulate and validate the period of time needed for the transferring the heated workpiece. At the given velocity $\dot{s}(t)=0.15 \mathrm{~m} / \mathrm{sec}$, the transferring time period is $15 \mathrm{sec}$.

\section{Selection of Geometric Parameters of Links}

For the designed Robot, the geometric parameters of links 3 and 4 plays the most important role since the total mass and inertia of the Robot are significantly effected by the links' mass and inertia. In order to choose the proper value of the lengths of links 3 and 4, the analysis of the kinematic manipulability index, $\omega=\sqrt{\operatorname{det}\left(\mathbf{J}_{E} \mathbf{J}_{E}^{T}\right)}$, where $\mathbf{J}_{E}=\frac{\partial \mathbf{P}_{E}}{\partial \mathbf{q}}$, is taken into account. For the Robot design, the index is calculated as $\omega=a_{3} a_{4}\left|\sin q_{4} \cos q_{2}\right|$.

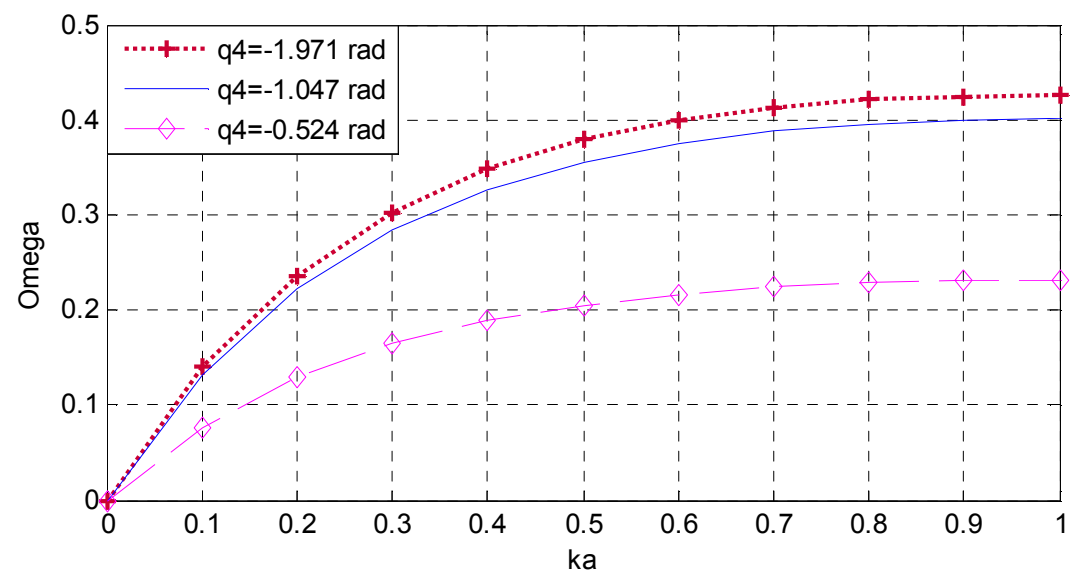

Fig. 9. The manipulability index versus $k a=a_{4} / a_{3}$ In essence, the index $\omega$ indicates of how close the Robot configuration is to the singularity. The value of $\omega$ depends on the value of variables $q_{2}, q_{4}$ but not on the other variables $d_{1}, q_{3}$, and $q_{6}$. The Robot will operate at maximum dexterity $(\omega \rightarrow \max )$ if $q_{2}=0$ and $q_{4}=-\pi / 2$. To maintain the dexterity level, the value of $q_{2} \rightarrow \pm \pi / 2$ and $q_{4} \rightarrow 0$ should not be selected as the range of rotation of joint 2 and joint 4 . In addition, it is also shown that the index $\omega$ depends on the 
geometric parameters $a_{3}$ and $a_{4}$. Fig. 9 shows that the value of $\omega$ varies along with the ratio of the length of links 4 and $3, k a=a_{4} / a_{3}$, in the case that $a_{3}+a_{4}=$ const and $q_{2}$ is given. The dexterity of the Robot is influenced by the value of $k a$. If a bigger $k a$ is selected, the value of $\omega$ will increase, but the stability margin of the system could be decreased. This is because the horizontal distance from the gravity centre of link 4 to $O_{1}^{\prime}$ and the link's mass and inertia increase. If $k a$ decreases, the value of the lower limitation of $q_{4}$ must be extended to maintain the dexterity of the Robot. Hence, the dexterity and the stability of the designed Robot must be taken into account simultaneously by selecting a suitable value of $\mathrm{ka}$. To make a trade-off between manipulability and stability, the lengths of links 3 and 4 are chosen as $a_{3}=0.73 \mathrm{~m}$ and $a_{4}=0.63 \mathrm{~m}$; the lower limitation of $q_{4}$ is checked with $q_{4 \min }=-1.971 \mathrm{rad}$.

\subsection{Quasi-static analysis}

Obviously, for arms of high load capacity, computation of the applied torques/forces required to bear the heavy payload and the gravity forces of links is significant for selection and validation of actuators. In this section, a quasi-static model is formulated and analysed to evaluate the applied torques/forces imposing on the active joints of the designed robot arm. The obtained value of the torques/forces is then employed to validate the geometric parameters and the operating pressure of two main hydraulic cylinders driving the joint number 3 and 4.

As for the designed robot arm, the vector of applied torques/forces $\boldsymbol{\tau}=\left[\begin{array}{lllll}F_{1} & \tau_{2} & \tau_{3} & \tau_{4} & \tau_{6}\end{array}\right]^{T}$, imposing on five active joints, can be computed as

$$
\boldsymbol{\tau}=\mathbf{J}_{p}^{T} \mathbf{p}_{p}+\sum_{i=1}^{6} \mathbf{J}_{i}^{T} \mathbf{p}_{i}
$$


where $\mathbf{p}_{p}$ is the payload imposing at the end arm point $\mathbf{c}_{p}(\mathbf{q}) ; \mathbf{p}_{i}$ is the gravity force acting at the mass centroid $\mathbf{c}_{i}(\mathbf{q})$ of the link $i ; \mathbf{J}_{p}=\frac{\partial \mathbf{c}_{p}(\mathbf{q})}{\partial \mathbf{q}}$ and $\mathbf{J}_{i}=\frac{\partial \mathbf{c}_{i}(\mathbf{q})}{\partial \mathbf{q}}$

Note that the vector $\tau$ in the above expression does not account for friction. They are the net torques/forces that balance the payload and the gravity forces of links.

Equation (7) can be proved by using the Principle of Virtual Work. Consider virtual displacements at individual joints, $\delta \mathbf{q}=\left[\begin{array}{lllll}\delta d_{1} & \delta q_{2} & \delta q_{3} & \delta q_{4} & \delta q_{6}\end{array}\right]^{T}$, and a virtual displacement at the arm tip, $\delta \mathbf{p}_{p}$. The virtual work $\delta W$ done by the forces and moments is given by

$$
\delta W=\boldsymbol{\tau}^{T} \delta \mathbf{q}-\mathbf{p}_{p}^{T} \delta \mathbf{p}_{p}-\sum_{i=1}^{6} \mathbf{p}_{i}^{T} \delta \mathbf{p}_{i}
$$

Substituting the differential relationships $\delta \mathbf{p}_{p}=\mathbf{J}_{p} \delta \mathbf{q}$ and $\delta \mathbf{p}_{i}=\mathbf{J}_{i} \delta \mathbf{q}$ into (8) yields

$$
\delta W=\left(\boldsymbol{\tau}-\mathbf{J}_{p}^{T} \mathbf{p}_{p}-\sum_{i=1}^{6} \mathbf{J}_{i}^{T} \mathbf{p}_{i}\right)^{T} \delta \mathbf{q}
$$

Therefore, for the above virtual work to vanish for arbitrary virtual displacements we must have

$$
\boldsymbol{\tau}-\mathbf{J}_{p}^{T} \mathbf{p}_{p}-\sum_{i=1}^{6} \mathbf{J}_{i}^{T} \mathbf{p}_{i}=0
$$

Notice that $\mathbf{c}_{i}(\mathbf{q})$ is determined with respect to the frame $O_{i}$ in the kinematic chain. Suppose that $\mathbf{c}_{p} \equiv \mathbf{p}_{E}$, the Jacobian $\mathbf{J}_{p}$ is computed as $\mathbf{J}_{p}=\frac{\partial \mathbf{f}(\mathbf{q})}{\partial \mathbf{q}}$

Equation (13) can be evaluated for any configuration of the robot in the configuration space. Notice that when the arm picks and lifts up a heated workpiece from the table of the furnace (the task B1), the arm tip reaches to a farthest point, and the effect of the gravity forces on the system 
maximizes. For this critical configuration, the applied torques imposing on joints 3 and 4 are calculated as $\tau_{3}=1,167.4 \mathrm{Nm}$, and $\tau_{4}=1,233.29 \mathrm{Nm}$ where $p_{p}=600 \mathrm{~N}, p_{1}=4,812.3 \mathrm{~N}$, $p_{2}=813 \mathrm{~N}, p_{3}=506.4 \mathrm{~N}, p_{4}=583.7 \mathrm{~N}, p_{5}=376.5 \mathrm{~N}$, and $p_{6}=730.3 \mathrm{~N}$. To meet the calculated torques $\tau_{3}$ and $\tau_{4}$ as required, hydraulic cylinders having the bore diameter $D=80 \mathrm{~mm}$ and using the operating pressure $P_{\text {oil }} \geq 200$ bar can be selected for driving the joints 3 and 4 .

\subsection{Structural analysis of the end-effector}

The deformation and stress contribution of the end-effector need to be investigated because the cross section of the griper geometry is smallest, as compared with the cross sections of links 3 and 4; the end-effector grips directly onto the heavy workpiece. Also, links 3 and 4 are actuated by strong hydraulic cylinders. By using the finite element method integrated in CAE software Autodesk Inventor (ANSYS Mechanical), the static stress and displacement distribution on the end-effector are computed and simulated (Fig. 10). Consequently, the maximum value of the stress and the deflection of the end-effector are determined to examine the safety factor and the loading capability of the robot. The end-effector is acted on by the external forces $p_{p}=600 \mathrm{~N}$. Other initial conditions required for the simulation running are inputted into the model.

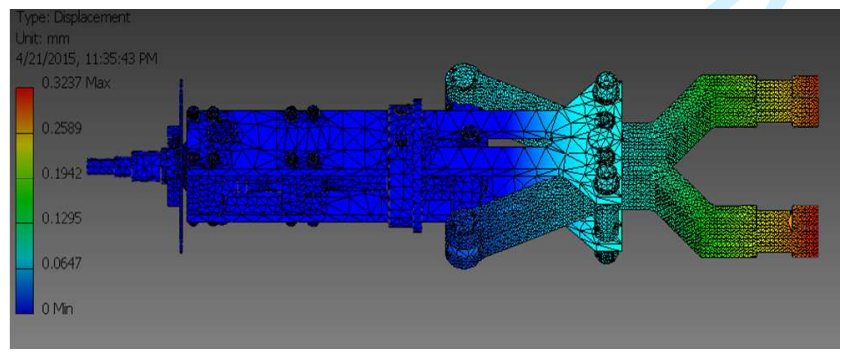

Fig. 10. Displacement of the end-effector 
The simulation results show that the maximum stress is $31.21 \mathrm{MPa}$ which is much lower than the yield strength of the designated material, $\sigma=99 \mathrm{MPa}$; the minimum safety factor is 3.15 which is greater than 2.73 - the allowed safety factor. These results show the loading capacity of the designed end-effector with respect to its material and geometry. The maximum value of the displacement is $0.3237 \mathrm{~mm}$. This is also meaningful in constructing the control algorithm and program. The programmer should consider and compensate this value inside the controller to increase the accuracy of the robot gripper.

\subsection{Functional test and cycle time analysis}

Fig. 11 shows pictures of the implemented robot with the following characteristics.

$\begin{array}{ll}\text { Robot footprint }[\mathrm{mm}]: & 1008 \times 757 \\ \text { Controlled axes: } & 5 \\ \text { Repeatability }[\mathrm{mm}]: & \pm 4.6 \\ \text { Mechanical weight }[\mathrm{kg}]: & 785 \\ \text { Maximum speed } & \\ \text { Joint } 1[\mathrm{~m} / \mathrm{s}]: & 0.8 \\ \text { Joint } 2[\% \mathrm{~s}]: & 20 \\ \text { Joint } 3[\% \mathrm{~s}]: & 14 \\ \text { Joint } 4[\% / \mathrm{s}]: & 14 \\ \text { Joint } 6[\% \mathrm{~s}]: & 45 \\ \text { Voltage } 50 / 60 \mathrm{~Hz} 3 \text { phase }[\mathrm{V}]: & 380 \\ \text { Voltage } 50 / 60 \mathrm{~Hz} 1 \text { phase }[\mathrm{V}]: & 220 \\ \text { Average power consumption }[\mathrm{kW}]: & 8\end{array}$

A series of functional tests performed on the robot arm, in which a comparison is carried out among numerical results, simulation results and experimental results giving a good match. The transforming time of a hot workpiece from the furnace to the die on the press machine is $20.4 \mathrm{sec}$ which is greater than $15.0 \mathrm{sec}$ - the simulation value obtained by the inverse kinematics analysis. However, this experimental value is still much lower than the allowed value $(25.0 \mathrm{sec})$. When the gripper grips and lift up a workpiece weighted $60 \mathrm{~kg}$, the measured deflection of the arm tip is $0.24 \mathrm{~mm}$ which lower than the value yielded from the simulation scenarios $(0.3237 \mathrm{~mm})$. 


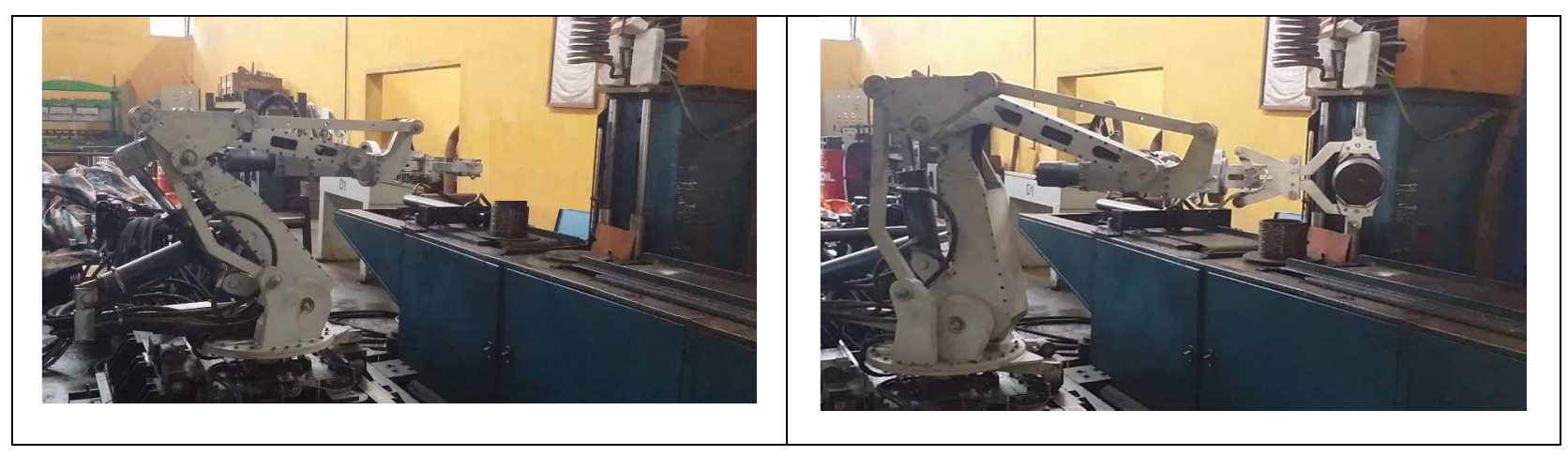

Fig. 11. Pictures of the implemented robot arm

In the experimental tests, dataset for production cycle time analysis is collected, in which 9

observations (sample size $=9$ ) are carried out. For this serial production, each production cycle is devided into six steps, and the time needed for each steps is measured correspondingly. Finally, the average production cycle time is determined. Tab. 2 shows a comparison of the manual cycle time and the auto cycle time. By using the robot, the average cycle time is reduced by $27.7 \%$ as compared with the average cycle time of the manual method.

Table 2. Cycle time comparison

\begin{tabular}{|l|c|c|}
\hline & $\begin{array}{c}\text { Manual cycle time } \\
\text { (Sec) }\end{array}$ & $\begin{array}{c}\text { Auto cycle time } \\
\text { (Sec) }\end{array}$ \\
\hline $\begin{array}{l}\text { Average processing time of the machines (heating and } \\
\text { pressing) }\end{array}$ & 103.5 & 103.5 \\
\hline Average loading time of raw material & 6 & 3.6 \\
\hline Average transferring time to the heating furnace & 22 & 17.8 \\
\hline $\begin{array}{l}\text { Average transferring time from the furnace to the press } \\
\text { machine }\end{array}$ & 25 & 20.4 \\
\hline $\begin{array}{l}\text { Average loading and unloading time of the part on the } \\
\text { press machine }\end{array}$ & 120 & 54.6 \\
\hline Total & 276.5 & 199.9 \\
\hline
\end{tabular}

\section{Conclusion}

A cost-effective robotized solution of automated workpiece handling for hot forging press manufacturing has been successfully investigated and implemented. The testing results show that the designed robotic system is capable of replacing workers to pickup, transfer and place 
workpiece among given places of the manufacturing system. By applying the solution, the average cycle time of the production has been reduced by $27.7 \%$ approximately.

In particular, a special mechanism of the robot arm was synthesized. By adding two successive parallel links in between an usual serial kinematic chain of manipulator, the DOFs of the mechanism has been reduced, and the orientation of the end-effector has been optimized. The computational validations and experimental tests have shown that the average value of the transferring time measured by experiments $(20.4 \mathrm{sec})$ was greater than the value calculated by simulation $(15 \mathrm{sec})$, but it was still less than the allowed limitation $(25 \mathrm{sec})$; the hydraulic cylinders (with bore diameter $D=80 \mathrm{~mm}$ and oil pressure $P_{\text {oil }}=200 \mathrm{bar}$ ) driving the joints 3 and 4 of the designed robot were properly selected; the maximum static deflection of the end-effector was calculated as $0.3237 \mathrm{~mm}$ which was greater than the value yielded by the experimental test $(0.24 \mathrm{~mm})$; the minimum safety factor was 3.85 which was greater than 2.73 - the allowed safety factor. These results demonstrate the loading capacity of the designed end-effector with respect to its material and geometry.

Dynamic modelling and analysis, and dynamic modelling - based optimization of geometric parameters for links of the robot will be the future work of this research. The effects of temperature field, vibrations, and other dynamic factors on the optimization of the designed robot will be considered in the future work as well.

Acknowledgment: This research is funded by Vietnam National Foundation for Science and Technology Development (NAFOSTED) under grant number 107.04-2017.09.

\section{References}

Boudella, M. E. A., Sahin, E., \& Dallery, Y., 2018. Kitting optimisation in Just-in-Time mixedmodel assembly lines: assigning parts to pickers in a hybrid robot-operator kitting system. International Journal of Production Research, 1-20. 
Carbone, G., \& Ceccarelli, M., 2005. A serial-parallel robotic architecture for surgical tasks. Robotica, 23(3), 345-354.

Chen, G., et al., 2012. Modular calculation of the Jacobian matrix and its application to the performance analyses of a forging robot. Advanced Robotics, 23 (10), 1261-1279.

Cherubini, A., et al., 2016. Collaborative manufacturing with physical human-robot interaction. Robotics and Computer-Integrated Manufacturing, 40, 1-13.

Denkena, B., \& Lepper, T., 2015. Enabling an industrial robot for metal cutting operations. Procedia CIRP, 35,79-84.

Ding, H., et al., 2017. Structure synthesis of 6-DOF forging manipulators. Mechanism and Machine Theory, 111, 135-151.

Dolgui, A., \& Pashkevich, A., 2006. Cluster-level operations planning for the out-of-position robotic arc-welding. International Journal of Production Research, 44(4), 675-702.

Dolgui, A., \& Pashkevich, A., 2009. Manipulator motion planning for high-speed robotic laser cutting. International Journal of Production Research, 47 (20), 5691-5715.

Faguo, Y., et al., 2008. Structure synthesis for forging manipulators. Proceedings of 7th World Congress on Intelligent Control and Automation, Chongqing, China, 400-403.

Forge, S., Blackman C., 2010. Helping hand for Europe: The competitive outlook for the EU robotics industry.

http://publications.jrc.ec.europa.eu/repository/bitstream/111111111/22080/1/jrc61539.pdf.

Foumani, M., Gunawan, I., \& Ibrahim, Y., 2014. Scheduling rotationally arranged robotic cells served by a multi-function robot. International Journal of Production Research, 52(13), 4037-4058.

Galante, G., \& Passannanti, G., 2006. Minimizing the cycle time in serial manufacturing systems with multiple dual-gripper robots. International Journal of Production Research, 44(4), 639-652.

Garcia, E., et al., 2007. The evolution of robotics research. IEEE Robotics \& Automation Magazine, 14 (1), 90-103.

Gougar, H., Cho, S., \& Prabhu, V., 2002. High performance loading robot design for a tooldelivery system. International Journal of Production Research, 40 (14), 3401-3424. 
Gultekin, H., Akturk, M. S., \& Karasan, O. E., 2008. Scheduling in robotic cells: process flexibility and cell layout. International Journal of Production Research, 46(8), 2105 2121.

He, Y., Stecke, K. E., \& Smith, M. L., 2016. Robot and machine scheduling with state-dependent part input sequencing in flexible manufacturing systems. International Journal of Production Research, 54(22), 6736-6746.

Huang, H. K., \& Lin, G. C., 2002. Development of a dual-robot system for prototype production. International Journal of Production Research, 40(15), 3751-3764.

Jin, Y., et al., 2009. Kinematic design of a family of 6-DOF partially decoupled parallel manipulators. Mechanism and Machine Theory, 44 (5), 912-922.

Karsak, E. E., 2008. Robot selection using an integrated approach based on quality function deployment and fuzzy regression. International Journal of Production Research, 46(3), 723-738.

Karsak, E. E., Sener, Z., \& Dursun, M., 2012. Robot selection using a fuzzy regression-based decision-making approach. International Journal of Production Research, 50(23), 68266834.

Kentli, A., \& Kar, A. K., 2011. A satisfaction function and distance measure based multi-criteria robot selection procedure. International Journal of Production Research, 49(19), 58215832 .

Kim, D. J., et al., 2014. System design and implementation of UCF-Manus - an intelligent assistive robotic manipulator. IEEE/ASME Transactions on Mechatronics, 19 (1), 225237.

Kim, D. K., Kim, H. J., \& Lee, T. E., 2017. Optimal scheduling for sequentially connected cluster tools with dual-armed robots and a single input and output module. International Journal of Production Research, 55(11), 3092-3109.

Kovács, A., 2016. Integrated task sequencing and path planning for robotic remote laser welding. International Journal of Production Research, 54(4), 1210-1224.

Liu, H. C., Ren, M. L., Wu, J., \& Lin, Q. L., 2014. An interval 2-tuple linguistic MCDM method for robot evaluation and selection. International Journal of Production Research, 52(10), 2867-2880. 
Michalos, G., et al., 2014. ROBO-PARTNER: seamless human-robot cooperation for intelligent, flexible and safe operations in the assembly factories of the future. Procedia CIRP, 23, 7176.

Michalos, G., Makris, S., Papakostas, N., Mourtzis, D., \& Chryssolouris, G., 2010. Automotive assembly technologies review: challenges and outlook for a flexible and adaptive approach. CIRP Journal of Manufacturing Science and Technology, 2(2), 81-91.

My, C. A. (2016). Inverse kinematics of a serial-parallel robot used in hot forging process. Vietnam Journal of Mechanics, 38(2), 81-88.

My, C. A., \& Parnichkun, M. (2015). Kinematics performance and structural analysis for the design of a serial-parallel manipulator transferring a billet for a hot extrusion forging process. International Journal of Advanced Robotic Systems, 12(12), 186.

Olsson, T., et al., 2010. Cost-efficient drilling using industrial robots with high-bandwidth force feedback. Robotics and Computer-Integrated Manufacturing, 26 (1), 24-38.

Pa, P.S., \& Wu, C.M., 2012. Design of a hexapod robot with a servo control and a man-machine interface. Robotics and Computer-Integrated Manufacturing, 28 (3), 351-358.

Paolo, F., and Botturi, D., 2008. Introducing service robotics to the pharmaceutical industry. Intelligent Service Robotics, 1 (4), 267-280.

Pham, D. T., \& Yeo, S. H., 1991. Strategies for gripper design and selection in robotic assembly. International Journal of Production Research, 29(2), 303-316.

Pinskier, J., Shirinzadeh, B., Clark, L., \& Qin, Y., 2018. Development of a 4-DOF haptic micromanipulator utilizing a hybrid parallel-serial flexure mechanism. Mechatronics, 50, $55-68$.

Sriskandarajah, C., \& Shetty, B., 2018. A review of recent theoretical development in scheduling dual-gripper robotic cells. International Journal of Production Research, 56(1-2), 817-847.

Su, J., et al., 2017. Grasping objects: The relationship between the cage and the form-closure grasp. IEEE Robotics \& Automation Magazine, 24 (3), 84-96.

Thomasson, O., Battarra, M., Erdoğan, G., \& Laporte, G., 2018. Scheduling twin robots in a palletising problem. International Journal of Production Research, 56(1-2), 518-542.

Tilley, J., 2017. Automation, robotics, and the factory of the future. https://www.mckinsey.com/business-functions/operations/our-insights/automationrobotics-and-the-factory-of-the-future 
Tor, S. B., et al., 2008. Knowledge-based functional design of industrial robots. International Journal of Production Research, 46 (16), 4501-4519.

Wei, Z., et al., 2017. Design and implementation of a leg-wheel robot: TRANSLEG. Journal of Mechanisms and Robotics, 9 (5).

Xue, Y. X., You, J. X., Zhao, X., \& Liu, H. C., 2016. An integrated linguistic MCDM approach for robot evaluation and selection with incomplete weight information. International Journal of Production Research, 54(18), 5452-5467.

Yan, C., et al., 2010. Kinematic modelling of a serial-parallel forging manipulator with application to heavy-duty manipulations. Mechanics Based Design of Structures and Machines, 38 (1), 105-129.

Yang, Y., Chen, Y., \& Long, C., 2016. Flexible robotic manufacturing cell scheduling problem with multiple robots. International Journal of Production Research, 54(22), 6768-6781.

Yildiz, S., Akturk, M. S., \& Karasan, O. E., 2011. Bicriteria robotic cell scheduling with controllable processing times. International Journal of Production Research, 49(2), 569583.

Youcef-Toumi, K., \& Kuo, A. T. Y., 1989. Design and control of a high-speed direct-drive manipulator. International Journal of Production Research, 27(3), 375-394. 